\title{
Website Interactivity in Malaysian and Australian Universities
}

\author{
Zanariah Jano ${ }^{1}$, Hanipah Hussin ${ }^{1}$, Aida Nasirah Abdullah ${ }^{1} \&$ Cheong Kar Mee ${ }^{1}$ \\ ${ }^{1}$ Centre of Languages and Human Development, Universiti Teknikal Malaysia Melaka, Hang Tuah Jaya, Durian \\ Tunggal, Melaka, Malaysia \\ Correspondence: Zanariah Jano, Centre of Languages and Human Development, Universiti Teknikal Malaysia \\ Melaka, Hang Tuah Jaya, 76100, Durian Tunggal, Melaka, Malaysia. Tel: 60-331-6946. E-mail: \\ zanariahjano@utem.edu.my
}

Received: January 16, 2015 Accepted: January 28, 2015 Online Published: June 5, 2015

doi:10.5539/ass.v11n17p14

URL: http://dx.doi.org/10.5539/ass.v11n17p14

\begin{abstract}
The extent to which web sites in Malaysian and Australian universities project their interactivity level was analysed. Content analysis was employed to measure the interactivity level. Twenty-six guidelines were selected and twenty university web sites from each country were randomly selected. The findings showed that human to marketer and human to human showed significant difference while human to content did not show any difference. This study will be an addition to web design literature and facilitate universities and individuals to develop effective strategies to elevate the image of universities in the global context. Future study should examine other interactivity dimensions which are not covered in this study and insights from web designer are also deemed important to ascertain the scenario behind the screen.
\end{abstract}

Keywords: cultural dimension, interactivity compliance, university, websites

\section{Introduction}

\subsection{Background}

As the online age has diminished international barriers, universities have to strive to be among the global players in order to attract stakeholders through the websites. Moreover, if the stakeholder base is international, knowing and acknowledging the aesthetic preferences of transnational clients on university websites show respect for the clients' cultures and might increase a company's networks, opportunity, and returns of investments. This, in turn, raises the question of how the universities are projected across the globe through their web design. In the perspective of an effective web-designing, a web page should have the features or interfaces that attract users to the sites. Website design can be an effective communicating tool through a vital dimension discussed in the literature which is interactivity.

Cho and Cheon (2005) propose the notion of looking at interactivity from both perspectives of human to message and human to human. Human to message interaction involves the interaction between users and content. The "keyword search", "multimedia entities", "software" and "games" are some of the features of this dimension. Meanwhile, human to human interaction denotes an interaction between users and receivers. Receivers could include other users or marketers. They conclude that human to message interaction and human to human interaction serve as umbrellas for various definitions and conceptions of interactivity. The present study utilizes the notion of human to content, human to marketer and human to human proposed by Cho and Cheon (2005).

\subsection{Relevant Scholarship}

\subsubsection{Interactivity}

Interactivity is an important entity for websites. Hallahan (2003) suggests that interactivity is a key factor in the relational processes that lead to relational outcomes online. Interactivity is the most salient advantage among distinguishing features of the Web (Cho \& Cheon 2005; Morris \& Ogan, 1996; Pavlik, 1996; Rafaeli \& Sudweeks, 1997).

Many conceptualisations of interactivity can be found in the literature. Some researchers define interactivity as a characteristic of a medium (Choi, Miracle, \& Biocca 2001; Lombard \& Snyder-Duch 2001; Roehm \& Haugtvedt 1999). Moreover, Public Relation theorists describe interactivity as features to build relationship (Gordon \& Berhow, 2009; Taylor \& Kent, 2004). Cho and Cheon (2005) propose the concept of human to message 
interaction and human to human interaction which serve as umbrellas for various definitions and conceptions of interactivity. Human to message interaction involves the interaction between users and content. The "keyword search", "multimedia entities", "software" and "games", are several features of this dimension (Cho \& Leckenby 1999; Ghose \& Dou 1998). Meanwhile, human to human interaction denotes interaction between users and receivers. Receivers refer to other users or marketers.

The current study adopts the concepts of human to message and human to human which are used by Cho \& Cheon (2005). The rationale of using these concepts is because the study aims to analyse interactivity in terms of both dimensions of human to message and human to human. The dimensions are vital in analysing the interactivity as a whole.

\section{(a) Human to content Interaction}

Several researchers note various web content to attract stakeholders; the inclusion of "search box" and the "privacy policy" (McMillan et al., 2008), "personalised e-mail notification" (Kadison, Weismann, Modahl, Lieu, \& Levin, 1998), "discount" and "free gift" (Cho \& Cheon, 2005; Delhagen, 1999)," client data-base" (Sonderegger, 1998). Sinha, Hearst, and Ivory (2001) conduct a study on the criteria for an award-winning website. 3000 websites in the areas of Science, Arts, Commerce, Living, and News are selected among the ones competing for the Webby Awards 2000. The websites are rated according to six criteria: content, structure and navigation, visual design, functionality, interactivity, and overall experience. The findings state that the content criterion is the best predictor of the overall experience criterion, whereas the visual design criterion is the worst predictor of the browsing experience. Hence, this study features that content plays more important roles than design.

Cho and Cheon (2005) conduct a study on the corporate websites of the United States, the United Kingdom, Japan and South Korea. The features analysed for human to content category are "keyword search", "personal choice helper", "virtual reality display", "dealer locator", "multimedia shows", "software downloading", "games" and "electronic coupon", "sweepstakes/prize", "interactive newsletters" and "choice of speed". Even though the study is done on the corporate sites, the changing role of universities from information-based to marketing based entity provide a justification on the adoption of certain features into the present study. The adoption of those features assist universities in promoting their brand globally. Hence, to uncover the ways in which universities adopt corporate websites features for their websites for various purposes is interesting. Through effective website, university can promote the products and services, facilitate education, impart information and build a responsible community of members among the stakeholders. All these activities constitute the answers to how universities can successfully communicate and support their missions and goals in branding experience through the website.

(b) Human to marketer and Human to human Interaction

Researchers use various keywords to describe interactivity for human to human dimension; "two-way communication" between source and receiver (Pavlik, 1996); "communication exchanges" (Rafaeli, 1988); "interpersonal interaction between the advertiser and consumer"; not only the traits that offer interactivity but also the promise of "a dialogue" or "mutual discourse"( Roehm \& Haugtvedt, 1999); "mouse-over effects and "searchable menus" (Wu, 2006); "site survey", "on-line order", "order status tracking", "on-line problem diagnostic", "electronic form enquiries", "comment", and "feedback" (Cho \& Cheon, 2005). The features of human to human with regards to user and marketer utilised by Cho and Cheon (2005) are adapted in the present study.

In general, the notion of interactivity is perceived differently by different researchers from different fields (HCI $\&$ usability, interactivity, marketing and public relation). Although interactivity is analysed for various purposes, the features which are analysed overlap. For example, universities can pursue interactive relationship by the inclusion of interactivity dimension (communication tools) and usability (browsing experience) to enhance interaction and communication between users and content, users and administrators and users and users. Consequently, these phenomena generate the marketing strategies for attracting prospective students. Thus, a combination of various fields should be reinforced to gear the marketing appeals. One apparent evident of an overlap of metrics is seen in the study of Perogaro (2006) whose relationship marketing metrics are similar to the interactivity metric used in Cho and Cheon's (2005) and the present study. Some of them include "e-mail", "student newspaper online", "multimedia show", "virtual tour" and "request application online". The overlap signifies that guidelines of interactivity features which embrace every field may be the solution for Web designers' reference to generate more effective marketing strategies. 


\subsection{Research Questions and Hypotheses}

This study utilises the following research questions.

\subsubsection{Research Questions}

The research questions chosen to guide this study are as follows:

RQ 1: Do websites of Malaysian and Australian universities differ or similar in projecting their interactivity dimension?

RQ 1a: Bo websites differ or similar in projecting the human to content category?

RQ 1b: Do websites differ or similar in projecting the human to marketer category?

RQ 1c: Do websites differ or similar in projecting the human to human category?

\section{Method}

This section illustrates the content analysis method, samples, procedure, and sampling procedure.

\subsection{Content Analysis of Websites}

Studying the content of websites is academically crucial but also challenging and interesting as it is an effective method for discerning patterns and themes in textual and graphic data. Websites are used to educate people, change people's minds, or compel action. As argued by Scharl (2006), studying and analyzing web content helps us to see what some real website producers and developers consider while making their websites.

Content analysis is chosen because it is used in various fields like marketing and media studies, literature, sociology, psychology, cultural studies, and educational research. Content analysis is a suitable method for answering most of the research questions in this study. Meanwhile, the quantitative method will be used in this study. Content analysis provides a quantified dimensional description of fields of representation. The methodology can be used to provide a background 'map' of a domain of visual representation (Leeuwen \& Jewitt, 2001, p. 27). A quantitative method for the content analysis of the websites is applied to investigate the availability of the units of analysis coded.

\subsection{Samples}

20 websites from Malaysian and Australian universities were selected. Australian universities may provide interesting and diversified ways of designing their websites because of the advanced state of the country in aspects and the use of the ICT. The results of this study are expected to show significant differences in the interactivity dimensions of Websites across these universities. In terms of cultural orientation, these countries are most likely to show observable cultural differences as they represent two distinct cultures (Hofstede, 1980; Hall, 1976). The samples were taken from the database of the Ministry of Education of Australia and the Ministry of Higher Education of Malaysia.

\subsection{Procedure}

The researcher chose the list of universities both in Malaysia and Australia. The universities were coded and given number in the Microsoft Excel spreadsheet. Then, the RANDBETWEEN function was used to randomly select 20 universities from each country. The second stage of selection involves the elimination of universities that do not fulfil the criteria. The universities must possess the following criteria:

- The web sites are good and well developed. They are not under construction.

- The web sites can be searched via the Yahoo and Google Search Engines.

- The web sites must have at least one type of social networking sites (Blog, Flickr, Face book).

The university websites have been filtered and 40 university websites from Malaysia and Australia were selected. Next, two coders who are fluent in both Malay and English analysed the website based on the given criteria. The coding process was done using SPSS application like the independent sample t-test to discover the significant differences among universities in Malaysia and Australia on the usability features. The next stage involved two coders namely Coder A and Coder B for the coding purposes. They were post graduate students at the Universiti Teknikal Malaysia Melaka, and they were trained by the researcher specifically for the purpose of this thesis. They were paid for incentives. To proceed with the coding tasks, all the coders were trained to code websites not included in the main study. Coder A and B eventually coded all the variables. The data were compared and inventory coding was reconciled. Then a check-list was produced and named as an 'Inventory Coding” 
For the next step, Coder A and B, independently, applied the coding whilst re-evaluating the websites. During the re-evaluation process, some modifications and adjustments whereby some minor changes were applied to the checklist as and where necessary, and finally the final inventory coding was produced. Several steps were applied for the content analysis of websites in this study as shown in Figure 1. The analysis features the progression from the homepage to the subsequent page.

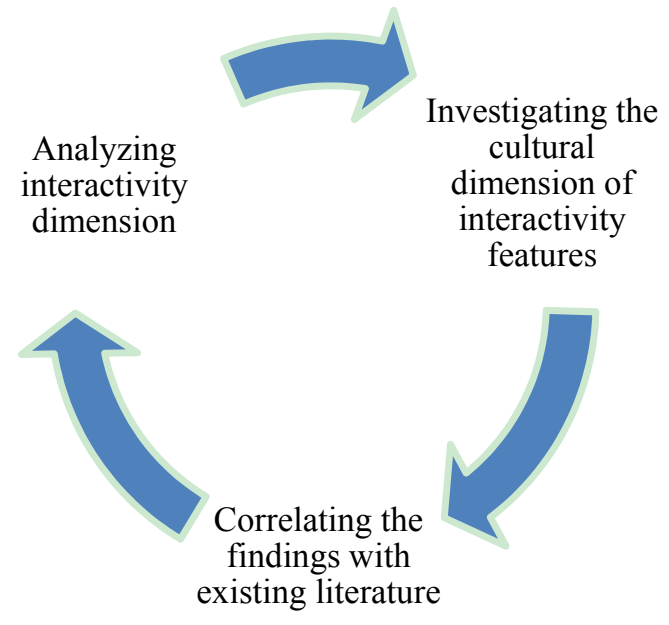

Figure 1. Procedure for analysis

\subsection{Data Collection}

\subsubsection{Analyzing Level of Interactivity}

The data for this analysis was collected from 20 websites of Malaysian and 20 Australian universities from December 6 to December 17, 2010. A coding instrument is developed to capture the level of interactivity of university websites in the Malaysian and Australian university websites. To address questions related to the level of interactivity of university websites, this study analyses the characteristics of university websites on the dimensions of human to content, human to marketer and human to human. Adopting Cho and Cheon's framework several indicators were analyzed namely Human to Content; Human to marketer; Human to Human.

The coding process was done using the independent sample t-test to discover the significant differences among universities in Malaysia and Australia on the interactivity features. Initially, the score of the interactivity categories were compared by an independent sample test (T-test). Then, the similar test was applied to compare the difference among the individual features in each category. The findings were reported in three sequence; overall features of category, university websites' performance for Malaysia and US and individual feature of each category. Specifically, a high level of interactivity is characterized by the score of the high end (5 or 7), moderate to well (3-4) and poor (1-2).

\section{Findings and Discussion}

\subsection{Interactivity}

$R Q$ 1a: How do the websites differ or similar in projecting the human to content category?

The features analysed are "personalisation"," interactive newsletter", "podcast", "keyword search", "virtual reality display", "branch locator", "multimedia show", "software downloading", "electronic coupons/vouchers", "RSS" and "competition/prize". In terms of individual features, three features of human to content show significant difference; "personalisation", "interactive newsletter" and "podcast". Malaysian university websites score higher for "personalisation" $(\mathrm{M}=4.1, \mathrm{SD}=2.45)$, than Australian universities $(\mathrm{M}=2.4, \mathrm{SD}=1.85)$ with $\mathrm{t}(58)$ $=2.97, \mathrm{p}<0.05$. Meanwhile, features for "interactive newsletters" show a higher score for Australian university websites $(\mathrm{M}=3.0, \mathrm{SD}=2.1)$ whereas the Malaysian websites feature a low rating $(\mathrm{M}=1.9, \mathrm{SD}=1.50)$ with significant difference of $\mathrm{t}(58)=-2.36, \mathrm{p}<0.05$. The similar scenario occurs for "podcast" as it shows a higher score for Australian university websites $(\mathrm{M}=3.6, \mathrm{SD}=3.0)$ whereas the Malaysian feature a lower rating $(\mathrm{M}=1.6$, $\mathrm{SD}=1.74)$ with significant difference of $\mathrm{t}(46.6)=-3.17, \mathrm{p}<0.05$. Table 1.0 illustrates the score for features of Human to content category. 
Table 1. T-test score for features of human to content category

\begin{tabular}{llllllll}
\hline Feature & \multicolumn{2}{l}{ Malaysia } & \multicolumn{2}{l}{ Australia } & & \\
& $\mathrm{M}$ & $\mathrm{SD}$ & $\mathrm{M}$ & $\mathrm{SD}$ & $\mathrm{t}$ & $\mathrm{df}$ & Sig (2-tailed) \\
\hline Personalisation & 4.1 & 2.45 & 2.4 & 1.85 & 2.97 & 58 & 0.00 \\
Interactive Newsletters & 1.9 & 1.50 & 3.0 & 2.1 & -2.37 & 58 & 0.02 \\
Podcast & 1.6 & 1.74 & 3.6 & 3.0 & -3.17 & 46.6 & 0.00 \\
Keyword Search & 6.8 & 1.09 & 6.9 & 0.55 & -0.45 & 58 & 0.66 \\
Virtual Reality Display & 1.8 & 1.99 & 1.6 & 1.71 & 0.28 & 58 & 0.78 \\
Branch Locator & 3.7 & 2.99 & 4.9 & 2.84 & -1.51 & 58 & 0.14 \\
Multimedia Show & 4.0 & 2.65 & 4.7 & 2.55 & -0.99 & 58 & 0.33 \\
Software Downloading & 2.9 & 1.98 & 2.8 & 2.59 & 0.11 & 54.2 & 0.91 \\
Electronic coupons/vouchers & 1.00 & 0.00 & 1.2 & 0.91 & -1.00 & 29 & 0.33 \\
RSS & 1.6 & 1.52 & 1.2 & 0.66 & 1.32 & 39.7 & 0.19 \\
Competition/prize & 1.7 & 1.88 & 1.8 & 1.88 & -2.06 & 58 & 0.84 \\
\hline
\end{tabular}

The findings of this study show that while "personalisation" scores higher for websites of Malaysian universities, "interactive newsletter" and "podcast" are poorly depicted. This is consistent to some degree with Cho and Cheon's (2005) study. They find that all features are common for web sites of the US and UK. Cho and Cheon (2005) attribute the findings to the cultural orientation of Hall's (1976) context in which the websites from low context culture tend to draw more information from the explicit content by means of interacting with it. However, the findings are in a stark contrast with Wu's (2011) findings in which personalisation and interactive newsletters do not show difference for the Chinese and English homepages. The reason is attributed to the U.S based, parent companies tend to "retain coherence, control and consistency of their different websites for different audiences rather than to customize their websites for different customers" (p. 42). This might suggest that the two features are not fully utilised by all universities in Australia due to the university policies.

\section{$R Q 1 b:$ How do the websites differ or similar in projecting the human to marketer category?}

Five features show significant difference in terms of human to marketer interactivity; "online order", "application status tracking", "new product survey", "interactive job placement" and "online discussion with administrators". Websites of Australian university $(\mathrm{M}=6.1, \mathrm{SD}=2.08)$ feature a higher depiction of "online order" than Malaysian university $(\mathrm{M}=4.7, \mathrm{SD}=2.77)$ with $\mathrm{t}(53.8)=-2.22, \mathrm{p}<0.05$. Similarly, Australian university websites $(\mathrm{M}=3.7, \mathrm{SD}=2.96)$ feature a higher depiction in terms of "new product survey" than Malaysian university websites $(\mathrm{M}=1.7, \mathrm{SD}=1.75)$ with $\mathrm{t}(47)=-3.24, \mathrm{p}<0.05$. Moreover, "interactive job placement" also features a higher depiction for Australian university websites than Malaysian with $\mathrm{t}(47.6)=-4.08, \mathrm{p}<0.05$. However, in terms of "application status tracking", Malaysian university websites $(\mathrm{M}=4.4, \mathrm{SD}=2.92)$ score higher than Australian university websites $(\mathrm{M}=2.5, \mathrm{SD}=2.61)$ with $\mathrm{t}(58)=2.61, \mathrm{p}<0.05$. Meanwhile, a striking and significant difference is noted for "online discussion with administrators", with web sites of Australian university score $(\mathrm{M}=5.7, \mathrm{SD}=2.43)$ than Malaysian university web sites $(\mathrm{M}=1.3, \mathrm{SD}=0.87)$ with $\mathrm{t}(36.3)=-9.36$, $\mathrm{p}<0.05$. Table 4.2 illustrates the score of features which show significant difference for human to marketer category for both websites of Malaysian and Australian university.

There are significant differences for "online order" and "online discussion with administrators" between the Australian and Malaysian university websites. Australian university websites score higher in terms of "online order" and "online discussion with administrators". Similarly, Cho and Cheon (2005) find that the U.S and U.K tend to feature more "online order" on their websites. This can be attributed to the diffusion of technology in the developed and developing countries. Australia is well advanced in its technology adoption as it is ranked high for new technology of cloud computing (Asia Cloud Computing Assoc, 2012). However in Malaysia, the e-payment technology might be slowly adapted by universities.

In terms of the projection of "application status tracking", Australian university websites score lower than the Malaysian. On the other hand, the Australian universities may include the "tracking status" in the portal, making it difficult to code. However, Cho and Cheon (2005) find that the U.S and U.K websites show more usage of such feature than the South Korean and Japan web sites.

New product survey is utilised more by the Australian university websites than the Malaysian. However, this value is contradicted in Cho and Cheon's (2005) study which indicate that new product survey is used more by the South Korean and Japan websites. This feature needs further research. 
Table 2. T-test score for human to marketer category

\begin{tabular}{llllllll}
\hline Feature & \multicolumn{2}{c}{ Malaysia } & \multicolumn{2}{c}{ Australia } & & & \\
& $\mathrm{M}$ & $\mathrm{SD}$ & $\mathrm{M}$ & $\mathrm{SD}$ & $\mathrm{t}$ & $\mathrm{df}$ & $\mathrm{Sig}$ (2-tailed) \\
\hline Online order & 4.7 & 2.77 & 6.1 & 2.08 & -2.22 & 53.8 & 0.03 \\
Application Status Tracking & 4.4 & 2.92 & 2.5 & 2.61 & 2.61 & 58 & 0.01 \\
New Product Survey & 1.7 & 1.75 & 3.7 & 2.96 & -3.24 & 47.03 & 0.00 \\
Interactive Job Placement & 3.2 & 2.57 & 5.4 & 1.55 & -4.08 & 47.6 & 0.00 \\
Online Discussion with Administrators & 1.3 & 0.87 & 5.7 & 2.43 & -9.36 & 36.3 & 0.00 \\
Site survey & 2.9 & 2.30 & 2.8 & 1.81 & 0.25 & 55 & 0.80 \\
E-mail links & 6.6 & 1.14 & 6.7 & 1.21 & -0.44 & 58 & 0.66 \\
Online Problem Diagnostic & 5.4 & 2.17 & 6.4 & 1.83 & -1.99 & 58 & 0.05 \\
Electronic form enquiries, comments and feedback & 5.3 & 2.45 & 5.7 & 2.28 & -0.55 & 58 & 0.59 \\
Product survey & 1.6 & 1.38 & 1.8 & 1.97 & -0.46 & 58 & 0.65 \\
\hline
\end{tabular}

However, in terms of "online discussion with administrators", the finding reflects Cho and Cheon's (2005) study which find that it is poorly depicted for Malaysian university websites. As for the "online discussion with administrators", Australian university websites have implemented the 24 hour online help-desk services on most web sites. Hence, this triggers the higher score for online communication with universities.

"Interactive job placement" shows low score for the Malaysian and much higher for the Australian university websites. Australian websites provide more efforts to minimise the distance between the classes. In addition, technical aspects could also contribute to the low interactivity as coding cannot be done for items featured in the portal or out of the boundary of layers surveyed or not interactive. Hence, the features are either not coded or they are not coded in the high score range. This could explain the low scores for these items.

"E-mail links", "online problem diagnostic", "electronic form enquiries, comments and feedback" show a good projection for both web sites while some crucial web features namely "site and product survey" are poorly utilized by both web sites. However, Cho and Cheon (2005) find that the UK and US websites use more of "online problem diagnostic" than Japan and Korean web sites while "electronic form enquiries, comments and feedback" do not show significant difference. A possible reason might be caused by the inclusion of the items in the portal which cannot be accessed by coders.

$R Q 1 c$ : How do the websites differ or similar in projecting the human to human category?

Out of three features, only one feature shows significant difference for human to human dimension; "send virtual postcard /share and bookmark / tell a friend". The Malaysian university websites $(\mathrm{M}=2.2, \mathrm{SD}=1.74)$ score higher than the Australian $(\mathrm{M}=1.3, \mathrm{SD}=0.92)$ with significant value of $\mathrm{t}(44)=2.61, \mathrm{p}<0.05$. Two features which do not show any significant difference are "surfer position" and "online chatting". Table 3 shows the score for features of human to human category across the websites of Malaysian and Australian university websites.

Table 3. T-test score for significant features of human to human category

\begin{tabular}{|c|c|c|c|c|c|c|c|}
\hline \multirow[t]{2}{*}{ Feature } & \multicolumn{2}{|c|}{ Malaysia } & \multicolumn{2}{|c|}{ Australia } & \multirow[b]{2}{*}{$\mathrm{t}$} & \multirow[b]{2}{*}{$\mathrm{df}$} & \multirow[b]{2}{*}{ Sig (2-tailed) } \\
\hline & $\mathrm{M}$ & SD & $\mathrm{M}$ & SD & & & \\
\hline $\begin{array}{l}\text { Send virtual postcard/share and bookmark/ tell a } \\
\text { friend }\end{array}$ & 2.2 & 1.74 & 1.3 & 0.92 & 2.61 & 43.9 & 0.012 \\
\hline Surfer position & 5.5 & 1.83 & 5.0 & 1.27 & 1.31 & 52 & 0.19 \\
\hline Online chatting with other users & 4.3 & 2.8 & 5.3 & 2.7 & -1.41 & 58 & 0.16 \\
\hline
\end{tabular}

"Send electronic postcard/tell a friend / share and bookmark" shows significant difference for websites of Malaysian and Australian university. The score for this feature is higher for Malaysian websites. This is consistent with Cho and Cheon's (2005) study which note the inclusion of more features of "electronic postcards" 
for the Japan and Korean web sites. The features are deemed essential for building virtual relationships among users. With the advent of social networking sites like Flickr, Friendster and Face book and chat technologies embedded within them, many college students "build and form social relationships online" (McMillan \& Morrison, 2006, p. 89). Moreover, $95 \%$ of college admissions offices are using at least one form of social media within 2009-2010 and this figure rises to 100\% in a recent study (Barnes \& Lescault, 2011).

In terms of "surfer position" and "online chatting", the Australian and Malaysian university websites provide a good platform like blogs, e-mail portal and forum area for users to interact and the inclusion of instant messaging services and Face book which have eased the online communication for users. Similarly, Cho and Cheon (2005) do not find significant difference between the U.S/ U.K and Japan/Korean websites in terms of online chat with other users. This shows that to some extent, the merging of values for some interactivity features for the two countries exists.

\section{Conclusion}

The evidence presented in the quantitative content analysis of the 30 Malaysian and 30 Australian university websites shows interesting findings. Even though the Australian university websites are representing the developed countries with an advanced technology, the projection of interactivity dimension, comprises human to content, human to marketer and human to human, is overwhelmingly low. Likewise, Malaysian university websites also show low features for the interactivity dimension. In terms of categories, human to content does not show any significant difference whereas, as expected, there are significant differences for human to marketer and human to human interactivity between Malaysian and Australian university websites. This study will be an addition to web design literature and facilitate universities and individuals to develop effective strategies to elevate the image of universities in the global context. Future study should examine other interactivity dimensions which are not covered in this study and insights from web designer are also deemed important to ascertain the scenario behind the screen.

\section{Acknowledgement}

This work was supported in part by a research fund of Ministry of Higher Education, Malaysia.

\section{References}

Asia Cloud Computing Assoc. (2012). Asia Cloud Forum. Retrieved January 19, 2013, from http://www.asiacloudforum.com/tag/Asia\%20Cloud\%20 Computing\%20Association

Barnes, N. G., \& Lescault, A. M (2011). Social Media Adoption Soars as Higher-Ed Experiments and Reevaluates Its Use of New Communications Tools. Working paper, University of Massachusetts Dartmouth.

Cho, C. H., \& Cheon, H. J. (2005). Cross Cultural Comparisons of Interactivity on Corporate Web sites: The United States, the United Kingdom, Japan and South Korea. Journal of Advertising Research, 34(2), 99-115. http://dx.doi.org/10.1080/00913367.2005.10639195

Cho, C. H., \& Leckenby, J. D. (1997). Internet-Related Programming Technology and Advertising. In M. Carole Macklin (Ed.), Proceedings of the 1997 Conference of the American Academy of Advertising (pp. 67-79).

Choi, Y. K., Gordon E. M., \& Frank, B. (2001). The Effects of Anthropomorphic Agents on Advertising Effectiveness and the Mediating Role of Presence. Journal of Interactive Advertising, 2(1). http://dx.doi.org/10.1080/15252019.2001.10722055

Delhagen, K. (1999). Online retail strategies: Ringing out '98, charging into '99. Forrester Report, 1(22). Retrieved March 13, 2010, from http://www.forrester.com

Ghose, S., \& Dou, W. (1998). Interactive Functions and their Impacts on the Appeal of Internet Presence Sites. Journal of Advertising Research, 38(2), 29-43.

Gordon, J., \& Berhow, S. (2009). University websites and dialogic features for building relationships with potential students. Public Relations Review, 35(2), 150-152. http://dx.doi.org/10.1016/j.pubrev.2008.11.003

Hall, E. T. (1976). Beyond Culture. New York. Anchor Press-Doubleday.

Hallahan, K. (2003). Review of Robert L.Heath. Handbook of Public Relations. Public Relations Review, 29(1), 94. http://dx.doi.org/10.1016/S0363-8111(03)00021-3

Kadison, H., Weismann, J. E., Modahl, M., Lieu, K. C., \& Levin, L. (1998). On-line Retail Strategies, Forrester Report 1/1. Retrieved October 5, 2012, from http://www.forester.com 
Lombard, M., \& Snyder-Duch, J. (2001). Interactive Advertising and Presence: A Framework. Journal of Interactive Advertising, 1(2). http://dx.doi.org/10.1080/15252019.2001.10722051

McMillan, J., Hoy, G., Kim, J., \& McMahan, C. (2008). A Multifaceted Tool for a Complex Phenomenon: Coding Web-based Interactivity as Technologies for Interaction Evolve. Journal of Computer-Mediated Communication, 13(4), 794-826. http://dx.doi.org/10.1111/j.1083-6101.2008.00420.x

Morris, M., \& Ogan, C. (1996). The Internet as Mass Medium. Journal of Computer-Mediated Communication, 1(4). http://dx.doi.org/10.1111/j.1460-2466.1996.tb01460.x

Pavlik, J. (1996). New Media Technology: Cultural and Commercial Perspectives. Boston: Allyn and Bacon.

Perogaro, A. L. (2006). A Study of Canadian University Home Pages examining relationship marketing tactics and website usability (Unpublished Dissertation Paper). University of Nebraska, Canada.

Rafaeli, S., \& Sudweeks, F. (1997). Networked Interactivity. Journal of Computer Mediated Communication, 2(4). http://dx.doi.org/10.1111/j.1083-6101.1997.tb00201.x

Roehm, H. A., \& Haugtvedt, C. P. (1999). Understanding Interactivity of Cyberspace Advertising. In D. W. Schumann, \& E. Thorson (Eds.), Advertising and the World Wide Web. Mahwah, NJ: Lawrence Erlbaum.

Sinha, R., Hearst, M., \& Ivory, M. (2001). Content or graphics? An empirical analysis of criteria for award-winning websites. Proceedings of the 7th Conference on Human Factors and the Web. Retrieved from http://webtango.berkely.edu/papers/hwf01/hwf01.htm

Sonderegger, K. E. (1998). Method for managing globally distributed software components. United States: Novell, Inc.

Taylor, M., \& Kent, M. L. (2004). Congressional websites and their potential for public dialogues. Atlantic Journal of Communication, 12(2), 59-76. http://dx.doi.org/10.1207/s15456889ajc1202_1

Wu, G. (2006). Conceptualizing and Measuring the Perceived Interactivity of Websites. Journal of Current Issues \& Research in Advertising, 28(1), 87-104. http://dx.doi.org/10.1080/10641734.2006.10505193

\section{Copyrights}

Copyright for this article is retained by the author(s), with first publication rights granted to the journal.

This is an open-access article distributed under the terms and conditions of the Creative Commons Attribution license (http://creativecommons.org/licenses/by/3.0/). 